This item was submitted to Loughborough's Research Repository by the author.

Items in Figshare are protected by copyright, with all rights reserved, unless otherwise indicated.

\title{
Rethinking the distinctions between old and new media: Introduction
}

PLEASE CITE THE PUBLISHED VERSION

https://doi.org/10.1177/1354856519863364

PUBLISHER

(c) the Authors. Published by SAGE Publications

VERSION

AM (Accepted Manuscript)

LICENCE

CC BY-NC-ND 4.0

REPOSITORY RECORD

Lesage, Frederik, and Simone Natale. 2019. "Rethinking the Distinctions Between Old and New Media: Introduction". figshare. https://hdl.handle.net/2134/38177. 


\title{
Rethinking the distinctions between old and new media: Introduction
}

Frederik Lesage, Simon Fraser University, Canada

Simone Natale, Loughborough University, UK

\begin{abstract}
Recent approaches to media change have convincingly shown that distinctions between old and new media are inadequate to describe the complexity of present and past technological configurations. Yet, oldness and newness remain powerful ways to describe and understand media change, and continue to direct present-day perceptions and interactions with a wide range of technologies - from vinyl records to Al voice assistants such as Siri and Alexa. How can one refuse rigid definitions of old and new, while at the same time retaining the usefulness and pertinence of these concepts for the study and analysis of media change? This introduction to the special issue entitled "Rethinking the Distinctions between Old and New Media" aims to answers this question by taking up the notion of biography. We argue that the recurrence of oldness and newness as categories to describe media is strictly related to the fact that interactions with media are embedded within a biographical understanding of time, which refers both to the lifecourse of people or objects and to the narratives that are created and disseminated about them. Employing this approach entails considering the history of a medium against the history of the changing definitions that are attributed to it, and more broadly, to considering time not only as such but also against the narratives that makes it thinkable and understandable.
\end{abstract}

Keywords: old media, new media, biographies of media, media change, remediation, life histories, narrative theory 


\section{Rethinking the distinctions between old and new media: Introduction}

In his famous presentation of the first model of iPhone in 2007, Steve Jobs chose to frame the gadget within wider trajectories across time. The iPhone, he told his audience, was an absolute novelty destined to change the way we conceive of communication; at the same time, however, it was a combination of technologies that already existed: an iPod with touch screen, a phone, and an Internet accessing device, all in one. Jobs also pointed to Apple's earlier successes: how the company, according to Jobs' narrative, had revolutionized the computer market through the Macintosh personal computer, and how with the iPod, Apple had not just introduced a new music device, but had irremediably changed the music industry. The key point Jobs wanted to convey was that the iPhone was more than a revolutionary new technology. It was an object embedded within a narrative time: a mythical past, embodied by Apple's track record of success; a reassuring present, represented through well-known and established technologies such as iPods, phones, and the Internet; and the mesmerizing future that Jobs' fervent performance confidently attributed to the company's latest gadget.

This Convergence special issue entitled "Rethinking the Distinctions between Old and New Media" examines how definitions of oldness and newness are attributed to technologies and artefacts during their lifetime. By illuminating places, cases, and contexts where distinctions between old and new media break down, the essays collected here interrogate how changing definitions of old and new shape specific media as well as their interrelations. In this introduction, we set up the overarching framework for such an undertaking, arguing that the recurrence of oldness and newness as categories to describe media is strictly related to the fact that interactions with media are embedded within biographical understanding of time. Employing the notion of biography, which refers both to the lifecourse of people or objects and to the narratives that are created and disseminated about them, we aim to emphasise that understandings of media emerge - like in the example of Steve Jobs' iPhone launch - within wider time trajectories and narratives through which the past, the present and the future are symbolically associated to technological objects and systems.

Novelty, in the history of technology, is a concept that encompasses centuries if not thousands of years of history. Alan Liu (2007) pointed out that the introduction of a new technology is always channeled symbolically through what he calls "narratives of media encounter." Such narratives may include Socrates' well-known dismissal of writing, as reported in Plato's Phaedrus (2011); the enthusiastic responses to the inventions of photography (Trachtenberg, 2007) and telegraphy (Czitrom, 1982) in the 1840s; as well as the discourse surrounding electricity in the last decades of the nineteenth century (Marvin, 1988). Conversely, oldness has also been attributed to media technologies and artefacts across history, often with rather interesting results. At the beginning of the twentieth century, for instance, spiritualist mediums took up obsolete photographic techniques to produce what they argued were images of spirits, because they considered older technology to be more 'authentic' (Coates, 1911). Also, feelings of nostalgia and increased authenticity were attributed to obsolete technologies after the shift from silent to sound cinema or from analog to digital sound recording (Bolter et al., 2006). 
Such historical precedents show the extent to which distinctions between 'old' and 'new' media are ingrained in discourses and debates about technology. In fact, after the emergence of the World Wide Web kindled in the 1990s a wave of overwhelming optimism about the prospects of digital media, many recognized the trace of previous enthusiasms about "new" media of the past (Gitelman and Pingree, 2003). Digital media came to be perceived as qualitatively new, sharply distinct from anything that had appeared before in human societies, and contrasted with other media, such as television and print media (Manovich, 2002). To many, these suddenly appeared, by comparison, obsolete and destined to be superseded. Over the last two decades, however, a range of criticisms and revisions also emerged in media studies that pointed to the artificiality and simplicity of such divides. Old and new media, it was argued, constantly intertwine and remediate each other (Bolter and Grusin, 1999; Balbi, 2015) in an incessant process through which novelty and oldness emerge as shifting and to some extent even arbitrary attributions (Peters, 2009; Acland, 2007). These bodies of work have compellingly shown that old and new media should be conceived as a relational concept: a range of ways through which people perceive and imagine their relationship and interactions with technology, rather than an attribute characterizing media as such (Natale, 2016a).

Communication and media scholars now face a conundrum. On the one side, distinctions between old and new media appear inadequate to describe the complexity of present and past technological configurations. On the other side, oldness and newness remain powerful ways to describe and understand media change, and continue to direct present-day perceptions and interactions with a wide range of technologies - from vinyl records to Al voice assistants such as Siri and Alexa. How can scholars, in this context, refuse rigid definitions, while at the same time retaining the usefulness and pertinence of these concepts for the study and analysis of media change?

The essays collected in this special issue advance a range of potential answers to this question. We have encouraged contributors to take up a complicated challenge: to develop critical approaches on distinctions between old and new media but also to question how this work can be fruitful and productive to the analysis. There could be no better platform for such endeavor than Convergence, a journal founded in 1995 whose subtitle still describes its remit as "The International Journal of Research into New Media Technologies."

While the featured articles provide a range of case studies and approaches to the overarching problem, this introductory essay aims at presenting an overall theoretical and methodological framework underpinning these efforts. We contend that the broader significance of media oldness and newness sits at the intersection of two complementary perspectives on media change. The first one, which we describe as the life history approach, posits that media are materially embedded in time and should be studied and understood in terms of their changing cultural and social characterizations. The second one, which we describe as the narrative approach, reminds us that media are not only technical systems and material objects, but also cultural constructions that shape and inform perceptions and representations of media and social change. We propose to employ the notion of biography as a way to combine and 
complement these two approaches. Biography denotes at once the life course of a person and a story about a person's life - a range of narratives that can be told, disseminated, and also used in support of specific visions and agendas. Applying the notion of biography to the debate on old and new media recognises that every interaction with technology is strictly dependent on biographical time, i.e. the process through which trajectories across time are mobilized in order to make sense of changes that affect our experiences and environment. In this, we take up James Stanyer and Sabina Mihelj's (2016) recent invitation to "take time seriously" in the study of communication and media, going beyond the identification of trends, temporal comparisons, or turning points, to address media change as a process that is continuously embedded in longer pathways through which time is conceived, understood and narrated.

\section{The Life History Perspective: de-essentializing media in time}

The first of the two approaches to media change that help illuminate distinctions between old and new media is the life history perspective. This involves investigating a medium's material history, much like following a person's transition from young to old - the 'life' of a medium.

There is an established tradition of using life histories of persons or groups of persons in humanistic or social scientific scholarship. What for some constitutes a weakness of the approach, namely the focus on details and particularities of individuals or groups over time (thereby limiting generalizability), has also been interpreted as one of its strengths (Bertaux, 1981). Life histories are a potent methodological strategy for situating people in a time and place, of giving an account of their existence in ways that embrace their specificity and their broader significance (Wengraf et al., 2002; Cavarero, 2000). This focus on specificities to historicize a person's becoming can also be applied to the life history of a medium but with different results: by focussing on the specificities of a technology, format, or artifact and their related social institutions, life histories of individual media can challenge its essentializations.

At least two important methodological innovations for telling life histories emerged in late 1980s and the 1990s. The first methodological innovation stemmed from cultural anthropology's turn to an analysis of the 'social life' or 'cultural career' of artefacts. As anthropologists developed an understanding of ethnographic fieldwork as multi-sited, 'following the thing' afforded "tracing the circulation through different contexts of a manifestly material object of study (at least as initially conceived), such as commodities, gifts, money, works of art, and intellectual property" (Marcus, 1998: 91). Ethnographic scholarship by the likes of Arjun Appadurai (1986) and Igor Kopytoff (1986) rejected a certain kind of material essentialism that ascribed stable social and cultural properties to artefacts. The life histories of 'things' as a methodological strategy showed how object properties such as 'commodity' were not fixed to the object but were instead 'processual'.

The second methodological innovation of this period was developed in the field of science and technology studies (STS). Projects such as the social shaping of technology (MacKenzie \& Wajcman, 1985) and the social construction of technology (Bijker et al., 1987) generated detailed case studies of individual technologies to problematize conceptions of technological innovation as a linear process of 'invention-innovation-diffusion' (Williams \& Edge, 1996: 874 ). By providing 
accounts of technological failures as well as successes these projects critiqued teleological views of progress. Moreover, the case studies of singular technologies undermined a generalized theory of 'Technology' or of technological devices as stable and consistent entities. Instead, these individual accounts of technologies demonstrated how they were part of contingent and shifting webs of social, cultural, political and/or economic relations.

When applied to a medium, these two innovations draw attention to the contingency of categories affixed to it. Of course, media scholarship had already tackled how to de-essentialise 'media'. Writing about broadcasting in the mid-1970s, Raymond Williams had critiqued any attribution of intentionality or of an intrinsic technological logic to media (Williams, 2003). In combination with this established scholarship, 'following the object' can be used to bridge production and consumption studies, as well as to capture the various stages of a media artefact or media technology's transition from commercial design, to distribution and consumption. An example of its successful deployment within a British Cultural Studies tradition was an investigation of media in home life "as a social and cultural as well as a technological event" (Silverstone and Haddon, 1996: 68). This approach to the domestication of technologies into the moral economy of the household rendered gradations and shades of commodification and consumption of media that had until then been neglected.

The significance of these approaches for the debate on old and new media is aptly demonstrated by some of the articles in this special issue. Michael Palm (2019) shows us how vinyl's career as cultural artefact can only be understood in light of its circulation within chains of industrial manufacture and commercial distribution that speak to deeper questions of the political economy of cultural production. We also see how the methodological strategy of life history can challenge common-sense categorical associations of a medium that reify specific cultural forms as specific technologies. For example, Aleksandra Kaminska's (2019) historiographic investigation of security printing renders visible the inherent biases that come with a conception of printing that privileges the codex as its dominant output. Likewise, Peter Unwin's (2019) case study of the various permutations of Edison's electric pen and its uses draw a more nuanced picture of how electrification was incorporated into manual inscription. Elsewhere in the issue we see how life histories of a medium problematize essentializing categorial dichotomies of the digital and the analogue, of media winners and losers, of media success and obsolescence (Bory, 2019). In short, investigations into the life history of a medium furthers the overall project of complexifying the material fixity of media and its relation to social, economic and cultural forces over time.

Part of the current challenge in telling contemporary life histories of a medium involves the growing interdependency and complexity of current media, making it harder to 'bracket' a specific medium from its surroundings. The moment of mass media as a (relatively) unproblematic category of investigation has given way to a far more diverse and complex range of media that can variously be called transmediality, intermediality, or hybridity (Thorburn and Jenkins, 2003). This raises the difficult task of dealing with a medium across a seemingly disparate range of objects and institutions. Understood from the perspective of time, this challenge requires a sensitivity to potentially divergent or discordant temporalities. One response to this challenge is that life histories of a medium can serve to draw connections across otherwise heterogeneous media 
landscapes. Just as life histories of people are not exclusively limited to individuals but can also be applied to social groups, life histories of a medium need not limit themselves to a single technology or artefact. In fact, as we have shown, media life histories challenge the very notion of a thing's disciplinary, material, and semantic stability.

Another response to this challenge is to draw attention to any medium's 'double articulation' i.e. media's dialectic tension between meaningful texts and technologies (Livingstone, 2007; Lievrouw, 2014). Much of media studies remains focused on texts independently of the material devices that support them. Just as importantly, STS scholars have for the most part made little efforts to address the particularities of media as more than just technologies (Wajcman \& Jones, 2012; Gillespie et al., 2014). By theorizing, without necessarily resolving, media's existence as socio-cultural institutions of both text and technology, life histories of media ask scholars to follow multiple and potentially conflicting trajectories in time.

\section{The Narrative Perspective: Situating Media in Narratives}

If the life history approach considers newness and oldness as changing definitions that are attributed to media across time, the second approach examines how such definitions are embedded in narrative patterns through which media's histories and present configurations are represented and perceived. A similar endeavor maps to a long tradition in the study of media and technology, going back to authors such as Leo Marx (1964), Joseph Corn (1986) and James Carey (1989), and more recently, Mosco (2004) and Flichy (2007), among others, who have explored how discourses about media are constructed, disseminated and received in the public sphere.

The narrative perspective understands media's oldness and newness as the mobilization of a range of established narrative tropes presenting change in terms of substitutions, interactions or tensions between the old and the new. A key thread of narrative theory has explored, moving through foundational works of authors such as Joseph Campbell (2001) and Vladimir Propp (2010), the recurring structures and patterns characterising a wide range of narratives in the most diverse media forms, genres, traditions, as well as linguistic and cultural contexts. The distinction between the old and the new, which has been used throughout history in regard with different media and practices, can be regarded as one of these tropes. As Balbi and Winterhalter (2013) have shown, in fact, the same trope of oldness vs newness appears in many other contexts - from professional environments to perceived divides between generations, from social habits to institutions in the public and private sector.

Importantly, narratives about old and new media are not mere 'stories' that circulate in the public sphere: they convey specific discourses about technology, politics, and society. For instance, cinema's founding myth of the "train effect," according to which early audiences panicked when exposed to the realistic power of film, provided a long-held vision about the medium's illusory power as well as a stereotyped representation of common people's understanding (or lack thereof) of technological innovation (Bottomore, 1999); and, as a recent study has shown, in postWWII France the novelty of television was underlined and effectively constructed to cover up and 
obliterate the medium's institutional and technological past in Nazi Germany (Weber, 2019). In this special issue, Manuel Menke and Christian Schwarzenegger (2019) aptly demonstrate that narratives of oldness and newness also help people negotiate the meaning of media for themselves or collectively with others. Drawing from approaches to media ideologies showing that people act on the media according to their attitudes and beliefs toward the media (Gershon, 2010), Menke and Schwarzenegger conducted qualitative in-depth interviews in Germany that stimulated participants to reflect on the beliefs, attitudes, and strategies they employed when they tried to make sense of media and their role in everyday affairs. Importantly, their research shows that their understandings of media emerge in terms of the perceived relationships between different media and between the participants' own life stories and biographies. Distinctions between 'new' and 'old' media, in other words, are part of the process through which interactions with technology in everyday life are perceived and negotiated as part of a narrative continuum encompassing previous habits and memories as well as new experiences and encounters.

Narratives of oldness and newness are often appropriated by political groups, private companies, and public institutions in order to convey specific visions and messages. An example is the case discussed in the opening of this article, which shows a corporation such as Apple incorporating this discourse to market their brand and products (Streeter, 2006). But a similar strategy can also be identified at wider levels, such as the (re-)building of national identities in the digital age. Think, for instance, of the narratives of entrepreneurship that made the Silicon Valley and the personal computer revolution a new iteration of the American dream; or the rediscovery of the figure of Alan Turing and the history of Bletchley Park in the United Kingdom, which located the country's contribution to the 'digital revolution' in a chronologically distant but symbolically near past in which the British empire dominated the world and the UK engaged in a courageous and allegedly solitary battle against Nazi Germany.

\section{Towards a biographical approach}

The previous sections developed a productive tension between media and temporality through two approaches to studying media and communication: life histories and media narratives. In this section we show how a biographical approach can combine these approaches to provide a theoretical and methodological framework for understanding oldness and newness as they relate to media.

Biography describes, on the first hand, the course of a person's life. It constitutes an act of making sense of the life of a person in terms of the passage of time; it is, in its most literal meaning, an inscribed life. Biographies of media entail, in this sense, examining life histories of specific media as multifaceted and contingent material processes of becoming that are entangled in relations of power and resistance (Lesage, 2013). There is, on the other hand, a second meaning to the word "biography." Biographies are also a literary genre, a form of contingent narrative turning historical characters, events, and things into stories to be written, told, and circulated (Caine, 2010). Even when no written text is involved, people's lives are elaborated into narratives that circulate through different channels, genres, and ways. Turned into biographies, the lives of individuals construct new meanings and signify other things (Benton, 2009; Furbank, 2000). They embody particular 
representations of a person's character, their temperament, personality, and skills, as well as of broader notions related to the character's profession and agency. Biographies of media must therefore also take into account the tensions and conjunctions that emerge in the narratives through which we make sense of media in time (Natale, 2016b).

As shown above, looking at definitions of oldness and newness in terms of media's life history means taking time as the key dimension of the analysis. Understanding what it means for a particular device to be 'old' or 'new' is, however, not just a matter of chronology: electronic digital computers, for instance, are often presented as part of 'new' media despite the fact that their introduction is roughly contemporary to television. One needs instead to examine the history of a medium against the history of the changing definitions that are attributed to it; in other words, to consider time not only as such but also against the narratives that makes it thinkable and understandable. As argued by Ricoeur (1984), after all, social understandings of time emerge through narratives that help people organise time and appropriate it within their own life and experience. It is in this regard that the narrative approach - and hence the second meaning of the word biography - becomes central to the study of distinctions between old and new media, and more in general to the study of media change.

This adds an additional layer to research in social anthropology, STS, and more recently media studies that propose that things, like people, are social agents whose meaning and function is constantly reconstructed across time (Balbi et al., 2016). The social lives of things are not only negotiated at an intersubjective level. They are also inscribed through a range of narratives that help people make sense of their relationship with material objects and the environment around them. In order to understand how media are integrated within everyday life and experience one needs to consider their biographies through a combination of their material becoming in time and the narratives for reading and interpreting these becomings. Below we develop four examples illustrating how this can work in practice, highlighting how the various papers in this special issue align with this approach.

\subsection{Media's deaths: examining understandings of media through time}

At least since the introduction of the web, the end of 'old' media such as television, the print book, and the newspaper has been forecasted numberless times by scholars, journalists and commentators (Ballatore and Natale, 2016). As media history shows, media rarely 'die': radio, for instance, did not disappear after the invention of television, and print books have survived numerous technical and social innovations throughout time. Yet the recurrence of the idea that a new technology 'kills' an old one tells us much about the way in which people understand media change through biography. Birth, deaths, beginning and ending are in fact key ways through which people make sense of their own lives (Olney, 1972). This suggests that the insertion of media within genealogical or chronological trajectories based on oldness and newness is complementary to the creation of personal and collective narratives that contribute to form the identity of individuals and groups (Cavarero, 2000; Neiger, Meyers, \& Zandberg, 2011). "Television is dead, the book is dead, and I do not feel so good either" - to paraphrase a famous Woody Allen quote. 
Scholars in media studies have often posed the question if media such as cinema (e.g. Gaudreault and Marion, 2015) or television (e.g. McRae, 2006) disappear or are still recognizable entities in a digital era. The main way to look at this problem has been to examine the present configuration of the media sector against the lens of existing and changing definitions of each individual medium. It is however impossible to pose these questions without considering the fact that the death of any medium has less to do with technological developments then with issues of social life and narrative. A powerful demonstration of how this is true is the way in which political parties such as the Pirates Party in Northern and Central Europe or the 5-Star-Movement in Italy have integrated this idea within their own political messages, presenting themselves as harbingers of innovation aligned with 'new media' and the web, while representing their political opponents as representatives of 'old media' and therefore of the traditional establishment (Natale and Ballatore, 2014; Treré and Barassi, 2015). These cases show that media are also social and cultural constructs that are mobilized by groups and individuals to convey specific messages. The 'death' of a medium is a matter for narratology and discourse analysis as much as for the study of media change; and because media change is in itself both a technological and a social phenomenon, this dimension should not be overlooked to enquire what constitutes contemporary media such as 'cinema' or 'television'.

As exemplified by the case of media 'deaths', a biographies of media approach entails engaging with the interplays taking place between and through media life histories and media narratives. While many of the papers in this special issue engage with this interplay, Unwin's (2019) article about the electric pen serves as an excellent example of such an approach: a 'new' invention is marketed through narratives that underline its continuity with older systems rather than as novelty or rupture. Meanwhile, the electric pen's own subsequent representation through tropes of failure and obsolescence are only made possible based on a definition of media winners and losers that is itself framed within a broader media history based on an epochal 'big-four'-"the inexorable transition from the spoken word, to the scribal word, to the printed word, and finally, to the digital word."

\subsection{Biographies of software: making sense of media materiality}

A growing body of scholarship that adapts methodologies such as infrastructural inversion (Bowker, 1994; Bowker and Star, 2000) and media archaeology (Huhtamo and Parikka, 2011) have revived attention to the materials of communication. While some have called for re-visiting and expanding definitions of what constitutes media materiality so as to encompass more than the conventional paraphernalia of communication infrastructure (Peters 2015, Parikka 2015), others have given greater attention to how material infrastructures are embedded in social, economic, and material spaces (Parks and Starosielski, 2015).

Biographies of media, in this regard, draw attention to how the material reality of media affords interpretive flexibility while also resisting or undermining other social or cultural interpretations. Software serves as an apt example of this tension. As argued by Wendy Chun (2011: 2-3), software are paradoxical objects: their seemingly invisible and 'virtual' character contrasts with 
their visible effects on material reality. People therefore find it difficult to understand software's impact on their everyday life, interpreting its functioning in personal ways and also through the use of well-known narrative patterns. Taina Bucher (2016) recently proposed the concept of algorithmic imaginary to describe this dynamic; yet this perspective takes in too little consideration how previous experiences with media shape this process. By examining software life histories in conjunction with the narratives that are constructed about them, the biographical approach tackles this gap.

A biography of Photoshop, for example, shows that material changes to its features over time as part of its various version upgrades prompted recurring debates about cultural value within the communities of practice who design and use it (Lesage, 2016). Similarly, Natale's (2019) own biographical account of Joseph Weizenbaum's early chatbot ELIZA shows how its material opacity led to its translation into a plurality of narratives that shaped people's understandings of Al and chatbots. An example from this special issue is Bory's (2019) examination of the narrativization of two formative events in Al's introduction to the popular imagination. Bory convincingly demonstrates how long-standing narratives of dematerialization and the ethereal mind developed in science fiction literature were deployed to veil Al's materiality and thereby reinforced discourses of technological evolution and perfection. Other contributions show that a similar discourse applies beyond the case of software: Kaminska's (2019) account of how security printing, as 'off-shoots' of conventional printing practices, materializes trust through strategic deployment of complexity and quality, and Palm's (2019) contribution about the industry of vinyl records raises difficult questions about how material categorical distinctions like the one between analogue and digital can obscure a deeper and more complex politics of material production and consumption.

\subsection{Steve Jobs is the message: biographies of people and media in parallel lines}

One of the characteristics of biographies of media is their relationship with biographies of individuals: media are understood and placed within time through narratives that closely resemble stories about people's lives, as shown by the use of metaphors such as the "birth" (Gaudreault and Marion, 2013), "death" (McRae, 2006) and "evolution" (Lehman-Wilzig and Cohen-Avigdor, 2004) of specific media. Further evidence of this is the way in which influential entrepreneurs and inventors are presented in contemporary discourses through biographical narratives that run in parallel, and in many ways overlap, with the histories of new media technologies to which they are associated.

As Ortoleva (1996) convincingly demonstrated, the lives of inventors represent a highly standardized biographical genre through which cultural ideas about technology, innovation, and invention emerge and circulate. A recent wave of significant studies explored how influential characters of the digital media industry have renewed the status of inventors as modern heroes (see, among others, Streeter, 2016; Morozov, 2012; Hoffmann et al., 2018). If seen through the biographies of media framework, it becomes clear that these public figures not only convey representations of entrepreneurship, genius and innovation: their life stories are metaphors to present and narrate media across time. 
Steve Jobs is perhaps the clearest example of this. The ultimate inventor-entrepreneur of our age, Jobs has been so closely associated with Apple's corporate history and legacy to become indissoluble with the company and the many gadgets that signaled its success. Jobs' widely-told capacity to push Apple towards constant innovation (see, for the most influential example, Isaacson, 2011) literally embodies the myth of constant newness that characterised new media discourses and ideologies throughout the last three decades. To make another example, the biographic recountings of Tim Berners-Lee's life closely follow the narrative pattern about the birth of the Web, which he is credited with inventing at Cern in 1989. His heroic story contributes to the formation of particular claims and views about the Web's newness and the change it ignited in various aspects of society and everyday life (Natale and Bory, 2017).

Thus, a biographical approach to media in time helps unveil the discursive complicity between the representation of notable individuals and the representation of media newness. Such dynamic concerns not just famous individuals. Dovey and Kennedy (2007), for instance, show that the biographies of game developers are told through the embodied incorporation of technical skills over a lifetime and, just as importantly, articulating power relations as distinctions between dominant and/or peripheral bodies and technologies. In their important contribution to this special issue, moreover, Menke and Schwarzenegger (2019) suggest that this applies to some extent to the lives of any individual media user- since forms of mediated communication, be they described as 'old' or 'new', shape the lives of virtually everybody. Through their empirical investigation of how individuals living in Germany perceive media change, their article shows that comparisons between what constituted 'old' or 'new' help people renegotiate the meaning of media for themselves and incorporate media in their everyday lives and identities.

\subsection{The limits of my practice are the limits of my medium: biographies of practice}

If, as Latour (2000: 250) claims, technological objects are incontrovertibly entwined with their conditions of production and are therefore more easily "tied to a circumscribed and well-defined spatiotemporal envelope," then media can never only be technological. A medium's doublearticulation as technology and content, as well as its articulation through narrative, generate entanglements that require multiple spatio-temporalities. Some of the conceptual tools that scholars have developed to cut through such a Gordian knot are drawn from practice theory. Media scholars have adapted elements of practice theory whose lineage runs through Wittgenstein's philosophical reflections on 'forms of life', the social theory of Pierre Bourdieu, and the more recent works of Theodor Schatzki (to name only a few). By focussing on practice as everyday life, this approach 'decentres' (Couldry, 2012: 36) media texts and technologies as media scholars' objects of investigation. This shift affords the means to put into perspective a much wider and more heterogeneous conception of media, while maintaining a theoretical focus on social and cultural conditions of possibility.

Biographies of media practice are of particular relevance to our contemporary condition. Our ability to narrate, synthesize and make sense of events that surround us, does not entirely escape our material and discursive situation. The very limitations of time and narrative as they pertain to 
social order are encapsulated in the question of practice. Ricoeur himself apprehended a future that might resist and even undermine our individual and collective abilities to configure everyday experiences into narratives - a future that the contemporary media manifold may be complicit in turning into a reality (Couldry and Hepp 2017: 114-115).

Minniti and Magaudda's (2019) essay in this special issue shows how a biography of practice approach can serve to re-imagine some of media studies' timeworn distinctions between 'new' and 'old' as well as between 'digital' and 'analogue'. By broaching 'retromedia' (media like vinyl records and polaroid cameras that are popularly considered 'old') as practice they are able to slip out of conventional chronological frames of reference that essentialize these media as old. Understood as practice, retromedia become processual and can be interpreted in a way "that keeps together media materiality, their meanings, and also the embodied activities and behaviours that are attached to them."

\section{Conclusion}

We have used this introduction to the papers collected in this special issue to propose an overall theoretical and analytical framework organised around the concept of biographies of media. Theoretically as well as methodologically, it is only by taking into consideration these two different dimensions and their mutual interactions that we can understand the role of newness and oldness in shaping media transformations and stabilities.

What is the benefit, however, of this conceptual and analytical work? Bringing together these two perspectives through the notion of biography is important not just because conceptualizations of oldness and newness continue to be key concepts to understand and discuss media change, but for two other important reasons.

The first reason is that biographies of media help us understand media and incorporate them into our everyday life. Media are part of the general texture of contemporary experience (Silverstone, 1999). They are part of what makes us human. Rather than avoiding or downplaying their personification (Lakoff and Johnson, 1980) - i.e. the processes through which a physical object is specified as being a person, so that a wide variety of experiences with nonhuman entities are comprehended in terms of human motivations, characteristics, and activities - we should investigate how such personification metaphors "allow us to make sense of phenomena in the world in human terms - terms that we can understand on the basis of our own motivations, goals, actions, and characteristics" (34). From this point of view, media newness and oldness are not considered objective states but nor are these categories 'mere' illusions that have no impact on the flow of everyday life.

The second reason is that media biographies circulate in the public sphere in ways that inform public debates and thus governance and policies of 'old' and 'new' technologies. The development of Web 2.0 illustrates this well. Web 2.0 was built on a rhetoric of "participatory culture" that depended on contrasting "new" media that opened up pathways for "active" users, citizen participations and grassroots movements, to "old" media where audiences were passive. 
On a technical level, Web 2.0 rhetoric advanced a linear and chronological narrative of technological advancement in the service of certain commercial interests, while papering over more complex and longstanding debates about how the Web's infrastructure should be developed and improved (Lesage and Rinfret 2015). At the level of users, the rhetoric of newness denied the Web's continuities with other incumbent media power. Behind the supposed miraculous power of user agency lied, as Van Dijck (2009) aptly recognised, a power structure in which users were embedded in vertical labour relations administered by digital platforms and the companies that owned it. Old/new narratives neglected the fact that television audiences or press readerships were never only passive spectators, as shown by a long tradition of studies of media effects and consumption, and that what was called "participation" was in fact a new business structure by which users were embedded in the vertical integration of content, social networking and advertising to the benefit of big digital corporations. Thus, the narrative that distinguished the idea of "active" users of new media to the "passive" audiences of old media underpinned a public debate that was oblivious of the excessive power that digital companies such as Google, Facebook, Apple and Amazon were constructing in online spaces.

While an ever-growing amount of scholarly research keeps drawing attention to these issues, there remains the pressing problem of how media governance and policy discourse on the Internet are still dominated by an imaginary beholden to commercial and technocratic interests (Mansell 2012). Merging life histories and narratives of media through the biographical approach to media presented here, in this sense, can draw attention to more nuanced ways to understand media at the intersection between time, media change, discourses and narratives. Together with the essays published here, moreover, we hope that it will provide a further encouragement for scholars, journalists and stakeholders to move away from rigid conceptions of oldness and newness, emphasising instead the constant change that shapes our relationship with media objects and technologies.

\section{References}

Acland CR (ed.) (2007) Residual Media. Minneapolis: University of Minnesota Press.

Appadurai A (1986) Introduction: Commodities and the Politics of Value. In: Appadurai A (ed.) The Social Life of Things: Commodities in Cultural Perspective. Cambridge: Cambridge University Press, pp. 3-63.

Balbi G (2015) Old and New Media: Theorizing Their Relationships in Media Historiography. In: Kinnebrock S, Schwarzenegger C and Birkner T (eds.) Theorien des Medienwandels. Köln: Halem, (pp. 231-249).

Balbi G and Winterhalter C (2013) Antiche novita: Una guida transdisciplinare per interpretare il vecchio e il nuovo. Salerno: Orthotes. 
Balbi G, Delfanti A and Magaudda P (2016) Digital Circulation: Media, Materiality, Infrastructures. An Introduction. Tecnoscienza 7(1): 7-15.

Ballatore A and Natale S (2016) E-Readers and the Death of the Book: Or, New Media and the Myth of the Disappearing Medium. New Media \& Society, 18(10), 2379-2394.

Benton M (2009) Literary biography: An introduction. Malden, MA: Wiley-Blackwell.

Bertaux D (ed.) (1981). Biography and Society: The Life History Approach in the Social Sciences. Beverly Hills, Calif: SAGE Publications.

Bijker WE, Hughes TP, \& Pinch T (eds). (1987). The Social Construction of Technological Systems: New Directions in the Sociology and History of Technology. Cambridge, Mass.: MIT Press.

Bolter JD and Grusin RA (1999) Remediation: Understanding new media. Cambridge, Mass.: MIT Press.

Bolter JD, Maclntyre B, Gandy M and Schweitzer P (2006) New Media and the Permanent Crisis of Aura. Convergence: The International Journal of Research into New Media Technologies 12(1): 21-39.

Bory, P (2019) Deep new: The Shifting Narratives of Artificial Intelligence from Deep Blue to AlphaGo. Convergence: The International Journal of Research into New Media Technologies. Epub ahead of print 12 February 2019. DOI: 10.1177/1354856519829679.

Bottomore S (1999) The Panicking Audience?: Early Cinema and the "Train Effect." Historical Journal of Film, Radio and Television 19(2): 177-216.

Bowker GC (1994) Science on the Run: Information Management and Industrial Geophysics at Schlumberger, 1920-1940. Cambridge, Mass: MIT Press.

Bowker GC and Star SL (2000) Sorting Things Out: Classification and its consequences. In Inside Technology. Cambridge, Mass.: MIT Press.

Bucher T (2016) The Algorithmic Imaginary: Exploring the Ordinary Affects of Facebook algorithms. Information, Communication \& Society 20(1): 30-44.

Caine B (2010) Biography and History. Basingstoke, UK: Palgrave Macmillan.

Campbell J (2004) The Hero with a Thousand Faces. Princeton, N.J.: Princeton University Press. 
Carey JW (1989) Communication as Culture: Essays on Media and Society. Boston: Unwin Hyman.

Carey JW and Quirk JJ (1970) The Mythos of the Electronic Revolution. The American Scholar 39(3): 395-424.

Cavarero A (2000) Relating narratives: Storytelling and selfhood. London New York: Routledge.

Chun WHK (2011) Programmed Visions Software and Memory. Software Studies. Cambridge, Mass. : MIT Press.

Coates J (1911) Photographing the Invisible: Practical Studies in Spirit Photography, Spirit Portraiture, and Other Rare but Allied Phenomena. Chicago, III.: Advanced Thought Pub.

Copeland J (2012) Turing: Pioneer of the Information Age. Oxford: Oxford University Press.

Corn JJ (1986) Imagining Tomorrow: History, Technology, and the American Future. Cambridge, Mass.: MIT Press.

Couldry N (2012) Media, Society, World: Social Theory and Digital Media Practice. Cambridge, UK: Polity.

Couldry N and Hepp A (2016) The Mediated Construction of Reality: Society, Culture, Mediatization. Cambridge, UK; Malden, MA : Polity Press.

Czitrom DJ (1982) Media and the American Mind: From Morse to McLuhan. Chapel Hill: University of North Carolina Press.

Flichy, P (2007) The Internet Imaginaire. Cambridge, Mass.: MIT Press.

Furbank PN (2000) The craftlike nature of biography. In: Law J and Hughes LK (eds) Biographical passages: Essays in Victorian and Modernist biography. Columbia: University of Missouri Press, pp. 18-27.

Gaudreault A and Marion P (2015) The End of Cinema?: A Medium in Crisis in the Digital Age. New York: Columbia University Press.

Gaudreault A and Marion P (2013) Measuring the 'double birth' model against the digital age. Early Popular Visual Culture 11(2): 158-177.

Gershon I (2010) Breaking Up Is Hard to Do: Media Switching and Media Ideologies. Journal of Linguistic Anthropology 20(2): 389-405. 
Gillespie T, Boczkowski PJ and Foot KA (2014) Introduction. In: Gillespie T, Jackson SJ, Boczkowski PJ, et al. (eds) Media Technologies: Essays on Communication, Materiality, and Society. Cambridge, Mass.: MIT Press.

Gitelman L and Pingree GB (eds.) (2003) New Media, 1740-1915. Cambridge, Mass.: MIT Press.

Hoffmann AL, Proferes N and Zimmer M (2018) "Making the World More Open and Connected": Mark Zuckerberg and the Discursive Construction of Facebook and Its Users. New Media \& Society 20(1): 199-218.

Huhtamo E and Parikka J (eds.) (2011) Media Archaeology: Approaches, Applications, and Implications. Berkeley: University of California Press.

Isaacson W (2011) Steve Jobs. New York: Simon \& Schuster.

Kermode F (2000) The Sense of an Ending: Studies in the Theory of Fiction. Oxford: Oxford University Press.

Kopytoff I (1986) The Cultural Biography of Things: Commoditization as process. In: Appadurai A (ed) The Social Life of Things: Commodities in Cultural Perspective (pp. 3-63). Cambridge: Cambridge University Press, pp. 64-91.

Latour B (2000) On the Partial Existence of Existing and Nonexisting Objects. In: Daston L (ed.) Biographies of Scientific Objects. Chicago: University Of Chicago Press, pp. 247-269.

Lehman-Wilzig S and Cohen-Avigdor N (2004) The Natural Life Cycle of New Media Evolution: Inter-Media Struggle for Survival in the Internet Age. New Media \& Society 6(6): 707-730.

Lesage F (2013) Cultural Biographies and Excavations of Media: Context and Process. Journal of Broadcasting \& Electronic Media 57(1): 81-96.

Lesage F (2016) Reviewing Photoshop: Mediating cultural subjectivities for application software. Convergence: The International Journal of Research into New Media Technologies 22(2): 215229.

Lesage F and Rinfret L (2015) Shifting media imaginaries of the Web. First Monday 20(10).

Lievrouw LA (2014) Materiality and Media in Communication and Technology Studies: An Unfinished Project. In: Gillespie T, Jackson SJ, Boczkowski PJ, et al. (eds) Media Technologies: Essays on Communication, Materiality, and Society. Cambridge, Mass.: MIT Press, pp. 21-51.

Liu A (2007) Imagining the new media encounter. In: Siemens RG and Schreibman S (eds) $A$ companion to digital literary studies. Malden, MA: Blackwell Pub., pp. 3-25. 
Livingstone S (2007) On the Material and the Symbolic: Silverstone's double articulation of research traditions in new media studies. New Media and Society 9: 16-24.

Kaminska A (2019) Don't Copy That: Security Printing and the Making of High-Tech Paper. Convergence: The International Journal of Research into New Media Technologies. Epub ahead of print 12 February 2019. DOI: 10.1177/1354856519845748

MacKenzie DA and Wajcman J (eds) (1985) The Social Shaping of Technology: How the Refrigerator Got Its Hum. Milton Keynes: Open University Press.

Magaudda P and Minniti S (2019) Retromedia-in-Practice: A Practice Theory Approach for Rethinking Old and New Media Technologies. Convergence: The International Journal of Research into New Media Technologies. Epub ahead of print 24 April 2019. DOI: $10.1177 / 1354856519842805$.

Manovich L (2002) The Language of New Media. Cambridge, Mass.: MIT Press.

Mansell R (2012) Imagining the Internet: Communication, innovation, and governance. Oxford: Oxford University Press.

Marcus G (1998) Ethnography Through Thick and Thin. Princeton, New Jersey: Princeton University Press.

Marvin C (1988) When Old Technologies Were New: Thinking about Electric Communication in the Late Nineteenth Century. New York: Oxford University Press.

Marx L (1964) The Machine in the Garden: Technology and the Pastoral Ideal in America. New York: Oxford University Press.

McRae P (2006) The Death of Television and the Birth of Digital Convergence: (Re)Shaping Media in the 21st Century. SIMILE: Studies In Media \& Information Literacy Education 6(2): 112.

Menke M and Schwarzenegger C (2019) On the Relativity of Old and New Media: A Lifeworld Perspective. Convergence: The International Journal of Research into New Media Technologies. Epub ahead of print 6 March 2019. DOI: 10.1177/1354856519834480

Morozov E (2012) Form and fortune: Steve Jobs's pursuit of perfection-and the consequences. The New Republic. Available at: https://newrepublic.com/article/100978/form-fortune-steve-jobsphilosopher (accessed 11 April 2019).

Mosco V (2004) The Digital Sublime: Myth, Power, and Cyberspace. Cambridge, Mass.: MIT Press. 
Natale S (2019) If Software Is Narrative: Joseph Weizenbaum, Artificial Intelligence and the Biographies of ELIZA. New Media \& Society 21(3): 712-28.

Natale S (2016a) There Are No Old Media. Journal of Communication 66(4): 585-603.

Natale S (2016b) Unveiling the Biographies of Media: On the Role of Narratives, Anecdotes and Storytelling in the Construction of New Media's Histories. Communication Theory 26(4): 431449.

Natale S and Ballatore A (2014) The Web Will Kill Them All: New Media, Digital Utopia, and Political Struggle in the Italian 5-Star Movement. Media, Culture \& Society 36(1): 105-121.

Natale S and Bory P (2017) Constructing the Biography of the Web: An Examination of the Narratives and Myths around the Web's History. In: Brügger N (ed.) Web 25: Histories from the First 25 Years of the World Wide Web. London: Peter Lang, pp. 29-42.

Neiger M, Meyers O and Zandberg E (2011) On Media Memory: Collective Memory in a New Media Age. Houndmills, Basingstoke: Palgrave Macmillan.

Olney J (1972) Metaphors of Self: The Meaning of Autobiography. Princeton, N.J.: Princeton University Press.

Ortoleva P (2009) Modern Mythologies, the Media and the Social Presence of Technology. Observatorio (OBS) Journal 3(1): 1-12.

Ortoleva P (1996) Vite geniali: Sulle biografie aneddotiche degli inventori. Intersezioni 1: 41-61.

Palm M (2019) Keeping what Real: Vinyl Records and the Future of Independent Culture. Convergence: The International Journal of Research into New Media Technologies. Epub ahead of print 26 March 2019. DOI: 10.1177/1354856519835485.

Parikka J (2015) A Geology of Media. Minneapolis: University of Minnesota Press.

Parks L and Starosielski N (2015) Signal Traffic: Critical Studies of Media Infrastructures. Champaign: University of Illinois Press.

Peters B (2009) And Lead Us not into Thinking the New Is New: A Bibliographic Case for New Media History. New Media \& Society 11(1-2): 13-30.

Peters JD (2015) The Marvelous Clouds. Chicago: University of Chicago Press.

Plato (2011) Phaedrus. Cambridge: Cambridge University Press.

Propp V (2010) Morphology of the Folktale. Austin: University of Texas Press. 
Ricoeur P (1984) Time and Narrative. Chicago: University of Chicago Press.

Silverstone R (1999) Why Study the Media? London: Sage.

Silverstone R and Haddon L (1996) Design and the Domestication of Information and Communication Technologies: Technical change and everyday life. In: Mansell $\mathrm{R}$ and Silverstone R (eds) Communication by Design: The Politics of Information and Communication Technologies. Oxford: Oxford University Press, pp. 44-74.

Stanyer J \& Mihelj S (2016). Taking Time Seriously? Theorizing and Researching Change in Communication and Media Studies. Journal of Communication 66(2): 266-279.

Streeter T (2016) Steve Jobs, Romantic Individualism, and the Desire for Good Capitalism. International Journal of Communication 9: 3106-3124.

Thorburn D and Jenkins H (2003). Rethinking Media Change: The Aesthetics of Transition. Cambridge: MIT Press.

Trachtenberg A (2007) Lincoln's smile and other enigmas. New York: Hill and Wang.

Treré E and Barassi V (2015) Net-authoritarianism? How web ideologies reinforce political hierarchies in the Italian 5 Star Movement. Journal of Italian Cinema \& Media Studies 3(3): 287304.

Unwin P (2019) “An Extremely Useful Invention”: Edison's Electric Pen and the Unraveling of Old and New Media. Convergence: The International Journal of Research into New Media Technologies. Epub ahead of print 28 May 2019. DOI: 10.1177/1354856519846790

Van Dijck J (2009) Users like you? Theorizing agency in user-generated content. Media, culture \& society, Sage Publications Sage UK: London, England 31(1): 41-58.

Wajcman J and Jones P (2012) Border Communication: Media Sociology and STS. Media, Culture \& Society 34(6): 673-690.

Williams R ([1974]2003) Television: Technology and Cultural Form. London: Routledge.

Williams R and Edge D (1996) The Social Shaping of Technology. Research Policy 25(6): 865899.

Weber AK (2019) Television as New Media: Raymond Millet's Télévision, Oeil de Demain (1947) and the Politics of French Experimental TV. NECSUS: European Journal of Media Studies. Available at https://necsus-ejms.org/television-as-new-media-raymond-millets- 
television-oeil-de-demain-1947-and-the-politics-of-french-experimental-tv/ (accessed 21 June 2019).

\section{Author biographies}

Frederik Lesage is Assistant Professor in the School of Communication at Simon Fraser University in Vancouver, Canada. He is the co-author of Masamune's Blade: A Proposition for Dialectic Affect Research (Peter Lang, 2016, co-authored with Peter Zuurbier). His work has also been published in journals including Fibreculture and Information, Communication \& Society.

Simone Natale is Lecturer in Communication and Media Studies at Loughborough University, UK. He is the author of Supernatural Entertainments (Penn State University Press, 2016) and editor of Photography and Other Media in the Nineteenth Century (Penn State University Press, 2018, co-edited with Nicoletta Leonardi) and Believing in Bits: Digital Media and the Supernatural (Oxford University Press, 2019, co-edited with Diana W. Pasulka). 